strategy. The method was a literature review alongside professional experience which when combined resulted in three key outcomes:

- The introduction of the concept of legitimacy and how this has the potential to be a key factor in hospice organisational change

- The highlighting of a model by Greenwood, Suddaby \& Hinings (2001) which provides a framework for institutional change

- The development of a new theoretical model that proposes a way of representing the nature of elements of hospice organisations. The model also outlines three options that explain some of the choices the hospice movement may make in addressing the need for change i) decoupling i.e. the intentional separation of activity from the accepted norms e. g. via a new partnership, ii) deinstitutionalisation followed by reinstitionalisation which is the process described by Greenwood, Suddaby \& Hinings (2002) identifying key stages of radically shifting institutional narrative or iii) the development of a new social movement.

The work is part of a larger study that aims to explore organisational factors influencing hospices' development of services for people with dementia. This first part of that work concludes that there is importance in understanding the nature of hospices as both old and new institutions (Selznick, 1957; Powell \& DiMaggio,1991). This theoretical lens provides a refreshing and insightful perspective on many of the challenges hospices are encountering as they face the future.

\section{P-233 USING VISUAL THINKING TO HARNESS THE RIGHT- BRAIN TO PLAN IN PALLIATIVE CARE}

Laura Myers, Duncan Newberry. Sue Ryder, Nettlebed, UK

\subsection{6/bmjspcare-2018-hospiceabs. 258}

Background Thinking in Western culture is traditionally leftbrain centred. Planning is often linear and depends on the drive, experience and expertise of individuals. Palliative care is a holistic discipline, but despite this there is often a reticence among some within the field to step outside the boundaries of established planning methods. Thinking creatively enables innovation, the cornerstone for developing services for those who need them. Enthusiasm to develop can be enhanced by using an unfamiliar, enjoyable and challenging method, such as visual thinking (Brand, 2017).

Aims To evaluate the use of visual thinking as a means to plan creatively and collaboratively in specialist palliative care.

Method A hospice education team used visual thinking as a planning tool to develop educational programmes. The technique involved the use of low cost materials, including rolls of brown paper and pens. The focus is on presenting thoughts in a visual way by using creative thinking.

Results From the visual thinking exercises, planning documents were written. These enable the concepts to be recorded, given structure and presented to others in a more formal way. The visual thinking work can be kept in the workspace as a summary of the work in progress or included in reports as a graphic illustration of the planning. The differing levels of expertise and experience of the team members were drawn together to develop plans. Colleagues who saw the visual thinking work in progress, expressed interest; one planning to use the method as the basis for interview material and another used the concept to develop presentation materials.

Conclusions Visual thinking has been helpful in planning within a hospice. It takes some courage to try a new technique. Showing it in practice helps colleagues to see its value. It takes preparation and time, something that is needed however planning is undertaken.

\section{P-234 EVERY PENNY COUNTS}

Thompson Koramoa. Isabel Hospice, Welwyn Garden City, UK

\subsection{6/bmispcare-2018-hospiceabs.259}

Background I started working at the hospice as Director of Finance in January 2017. This was my first role working for a hospice and was a steep learning curve. The Times (2018) reported that charities are missing out on claiming gift aid. Weakley (2018) stated this amounts to over 600 million of potential funds for charities. There was a cumbersome system and lack of understanding of the advantages of gift aid had resulted in a backlog and missed opportunities to increase income by claiming this tax break. This was a huge challenge. However, this was a form of revenue which could not be ignored in a climate where palliative needs of our community are increasing and every penny counts towards their care.

Method A clear guide was produced to create an understanding of all issues raised and an action plan set up through a collaborative process. This included education to understand the importance of gift aid to our charity thus motivating the fundraising and retail team to get results. Crucially we sourced a team of volunteers to review over 14000 donor declaration forms in preparation for input into an electronic database. We also created a streamlined system to allow for quarterly claims and provided training.

Result We are now in a much better place. The pride created within our team when our first claim from the backlog came in was palpable. There is now a vibrant culture in championing gift aid. All HMRC queries were resolved and potential penalties avoided. The backlog has been cleared and a robust streamlined system is in place. Crucially our retail gift aid has doubled in 12 months. We have motivated teams who work collaboratively to get results ultimately benefiting the care we give.

\section{P-235 THROWING OUR HAT IN THE RING: TENDERING FOR SPECIALIST PALLIATIVE CARE SERVICES}

Helen Birch, Karen Groves. Queenscourt Hospice, Southport, UK

10.1136/bmjspcare-2018-hospiceabs. 260

Background In 2015 the local NHS Integrated Care Organisation put community services out to tender across two NHS Clinical Commissioning Groups (CCGs), a population of 235,000. This included specialist palliative care team (SPCT) for hospital and community and Consultants. The SPCT were an integral part of the local integrated service, the risks to patients and families of not having a seamless service would be detrimental. In 2016 two individual providers won the 